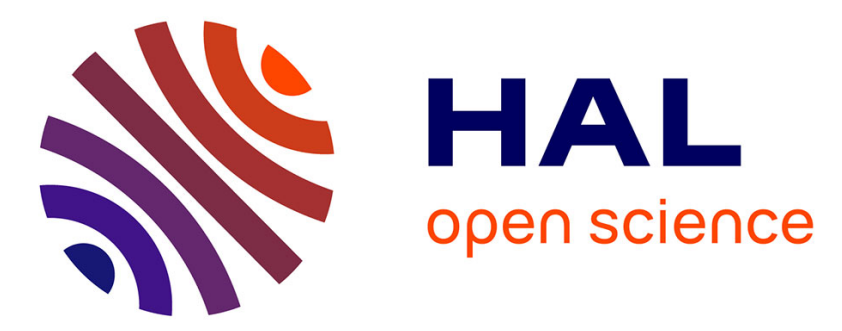

\title{
Thermal Properties of Some RE1-xEAxMnO3 Compounds
}

J. Liebe, E. Kraus, L. Haupt, K. Bärner, P. Mandal, I. Medvedeva, E. Gmelin, R. Helmolt

\section{- To cite this version:}

J. Liebe, E. Kraus, L. Haupt, K. Bärner, P. Mandal, et al.. Thermal Properties of Some RE1xEAxMnO3 Compounds. Journal de Physique IV Proceedings, 1997, 07 (C1), pp.C1-635-C1-636. 10.1051/jp4:19971262 . jpa-00254972

\section{HAL Id: jpa-00254972 https://hal.science/jpa-00254972}

Submitted on 1 Jan 1997

HAL is a multi-disciplinary open access archive for the deposit and dissemination of scientific research documents, whether they are published or not. The documents may come from teaching and research institutions in France or abroad, or from public or private research centers.
L'archive ouverte pluridisciplinaire HAL, est destinée au dépôt et à la diffusion de documents scientifiques de niveau recherche, publiés ou non, émanant des établissements d'enseignement et de recherche français ou étrangers, des laboratoires publics ou privés. 


\title{
Thermal Properties of Some $\mathrm{RE}_{1-x} \mathrm{EA}_{x} \mathrm{MnO}_{3}$ Compounds
}

\author{
J. Liebe, E. Kraus, L. Haupt, K. Bärner, P. Mandal*, I.V. Medvedeva**, E. Gmelin*** \\ and R.v. Helmolt****
}

IV. Phys. Institute, University of Göttingen, Bunsenstr. 11-15, 37073 Göttingen, Germany

* Saha Institute of Nuclear Physics, 1-AF Bidhannagar, Calcutta, 700064, India

** Institute for Metal Physics, Kovalevskaya Str. 18, 620219, Ekaterinburg, Russia

*** Max-Planck-Insitut für Festkörperforschung, Postfach 800665, 70506 Stuttgart, Germany

**** Siemens AG, Corporate Research and Development, P.O. Box 3220, 91050 Erlangen, Germany

\begin{abstract}
The Seebeck- effect and the thermal diffusivity $\kappa$ of epitaxial layers of $\mathrm{La}_{0.67} \mathrm{Ca}_{0.33} \mathrm{MnO}_{3-\delta}$ and bulk samples of $\mathrm{Nd}_{0.67} \mathrm{Sr}_{0.33} \mathrm{MnO}_{3-\delta}$ were investigated in the temperature range $35 \mathrm{~K}<\mathrm{T}<300 \mathrm{~K}$ using the time resolved thermoelectric power (flash) method. In the temperature regime of the high magnetoresistance (GMR) which is close to the maximum resistivity $\rho_{\max }$ of the La-Ca compound, we find a sign change of $\mathrm{S}(\mathrm{T})$ and a step in heat conductivity which we attribute to a temperature - induced metal-insulator transition at about $80 \mathrm{~K}$. For $\mathrm{Nd}_{0.67} \mathrm{Sr}_{0.33} \mathrm{MnO}_{3-\delta} \mathrm{such}$ a transition is also observed, but around $160 \mathrm{~K}$; here $\mathrm{S}(\mathrm{T})$ is always positive except for a gradual sign change at 370 $\mathrm{K}$ and the changes in $\kappa$ are also more gradual. For temperatures above $\rho_{\max }$ we find evidence of a spin glass like state in both cases.
\end{abstract}

\section{TEMPERATURE INDUCED ORDER-ORDER TRANSITION}

Magnetization measurements have shown that while stoichiometric $\mathrm{La}_{0.67} \mathrm{Ca}_{0.33} \mathrm{MnO}_{3-\delta}$ is a double exchange ferromagnet, oxygen deficient samples, e.g. La ${ }_{0.67} \mathrm{Ca}_{0.33} \mathrm{MnO}_{3-\delta}, 0 \leq \delta \leq 0.3$ exhibit a sequence of different magnetically ordered phases with decreasing temperature, i.e. spin glass like (sg), antiferromagnetic (afm) and canted [1]. While thermally activated, i.e. semiconducting behaviour of the resistivity is found in the spin-compensated phases, though with different temperature dependences, for the magnetic phases with a ferromagnetic component the conductivity is higher and metallic, which produces the resistivity maximum. The heat conductivity (fig. 1, La-Ca compound) also discriminates between the magnetically ordered and disordered phases : note the jump in $\kappa$ at the canted-afm transition at $\mathrm{T}_{1}=80 \mathrm{~K}$ and the more continuous drop in $\kappa$ for the afm-sg like transition, $\mathrm{T}_{a}$; when paramagnetism is finally installed at $\mathbf{T}_{f}, \kappa$ increases again. All this suggests that the large GMR found close to the maximum resistivity is connected with a field-induced change of the afm state into the canted state, accompanied by a of change in conductivity type from insulating to metallic $[1,2]$. For the pressure dependence of the order-order transition temperature in $\mathrm{Nd}-\mathrm{Sr}, \mathrm{T}_{1}$, which is usually equivalent to a field dependent change, we find $\frac{d T_{1}}{d p}=2.4 \frac{K}{k b a r}$. The thermoelectric power practically only differentiates between the magnetically ordered metallic and the semiconducting states, through a sign change for the La-Ca compound [2] and through a different sign of slope $\frac{d S}{d T}$ in the case of the Nd-Sr compound; there is, however, a sign change of $\mathrm{S}(\mathrm{T})$ close to $\mathrm{T}_{f}$ for $\mathrm{Nd}-\mathrm{Sr}$. For the La-Ca compound in the thermally activated region $\mathrm{S}$ becomes a constant suggesting polaron transport [2].

\section{SPIN GLASS LIKE STATE}

Specific heat capacity measurements on the La-Ca epitaxial layer were not available; however, a small dip in the thermal diffusivity is observed at $120 \mathrm{~K}$ [2], suggesting a heat capacity peak as $\mathrm{D}_{T}=\frac{\kappa}{\rho C_{V}} \cdot \mathrm{C}_{p}(\mathrm{~T})$ of $\mathrm{Nd}-\mathrm{Sr}$ reveals a peak around $240 \mathrm{~K}$ which we have to interpret as an afm - sg transition; also there is a change of slope of $\rho(\mathrm{T})$ at this temperature. At $160 \mathrm{~K}$ there is no anomaly in $\mathrm{C}_{p}(\mathrm{~T})$, as we expect for a magnetic order-order transition; also, the magnetic moment is near zero for all temperatures between $160 \mathrm{~K}$ and $450 \mathrm{~K}$, consistent with compensated magnetic 
states in this temperature range. Further evidence for the sg-like state comes from resistivity measurements $\rho(T)$ : we observe a second resistivity peak around $415 \mathrm{~K}$ which probably signals the sg-pm transition [3]. While the sequence of long range ordered magnetic phases have been predicted to occur in double exchange systems by de Gennes, the spin random phase at higher temperatures has been tentatively connected with thermally activated random atom displacements [4].

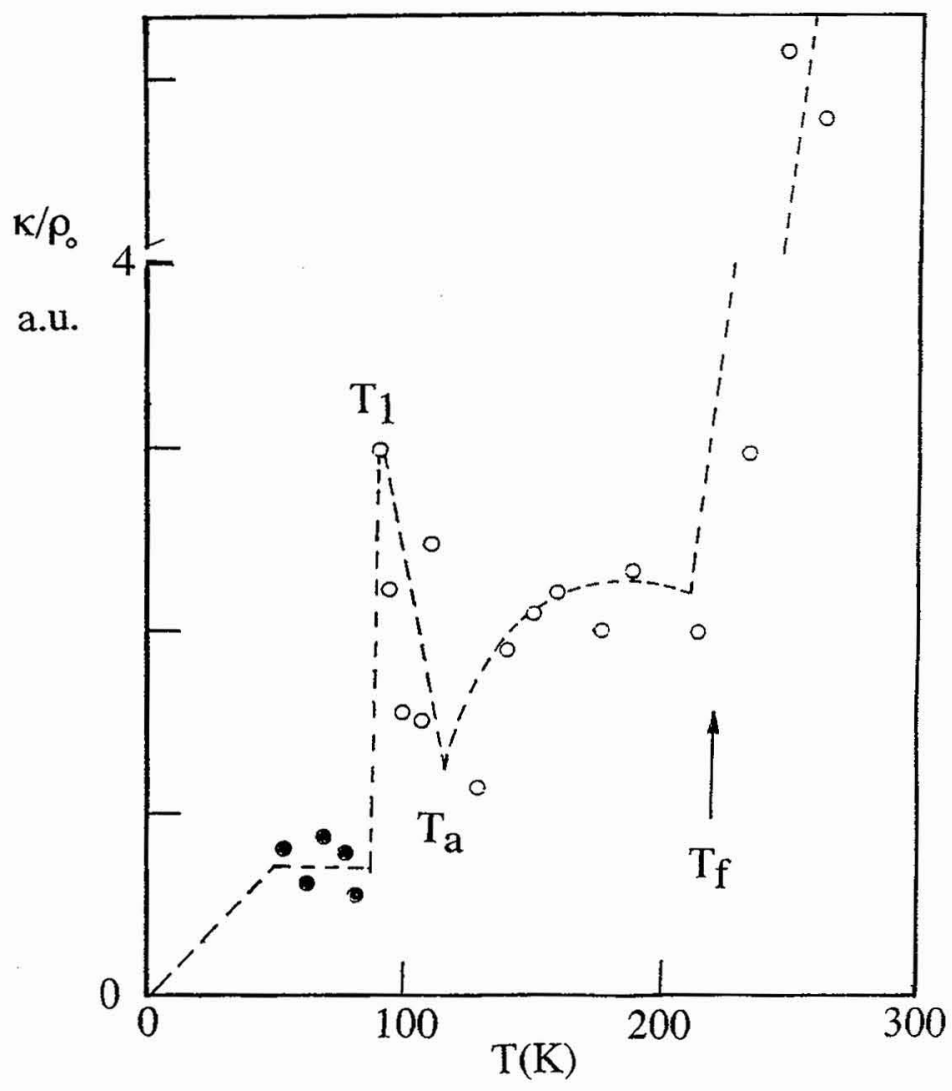

Figure 1 Heat conductivity $\kappa$ of $\mathrm{La}-\mathrm{Ca}$ compound divided by density $\rho_{0}$ versus temperature $\mathrm{T}$

$\mathrm{T}_{f}$ freezing temperature, $\mathrm{T}_{a}$ spin glass-antiferromagnetic transition, $\mathrm{T}_{1}$ afm-canted order-order transition

\section{References}

[1] R.v. Helmolt, J. Wecker, K. Samwer, K. Bärner, J. Magn. Magn. Mater. 151 (1995) 411

[2] J. Liebe, E. Kraus, L. Haupt, P. Mandal, K. Bärner, R.v. Helmolt, J. Appl. Physics Letters 68, No.17 (1996)

[3] P. Mandal, private communication

[4] P. Mandal, K. Bärner, R.v. Helmolt, L. Haupt, A.G.M. Jansen, subm. Phys. Rev. Letters 1996 